\title{
Expression of type III collagen mRNA in renal biopsy specimens of patients with idiopathic membranous glomerulonephritis
}

\author{
M S Razzaque, T Taguchi
}

\begin{abstract}
Aim-To investigate the distribution of type III collagen in membranous glomerulonephritis (MGN); to identify the cells responsible for the synthesis of $\alpha 1$ (III) mRNA.

Method-The distribution of type III collagen was studied by immunohistochemistry in 10 renal biopsy specimens, histologically diagnosed as MGN, and five control renal tissue samples obtained at surgery. Synthesis of $\alpha 1$ (III) mRNA was detected by non-radioactive in situ hybridisation.

Results-On immunohistochemistry, type III collagen was not observed in the control glomeruli, but was present focally in the glomeruli in samples from patients with MGN. No specific hybridisation signal for $\alpha 1$ (III) mRNA was found in the control glomeruli on non-radioactive in situ hybridisation. By contrast, positive signals for $\alpha 1$ (III) chain mRNA were detected in glomerular epithelial cells and mesangial cells in MGN tissue samples.

Conclusion-These data suggest that additional synthesis of type III collagen by intraglomerular cells contributes to the changes in the glomerular basement membrane characteristic of MGN.

(f Clin Pathol: Mol Pathol 1996;49:M40-M42)
\end{abstract}

Keywords: type III collagen, membranous glomerulonephritis, immunohistochemistry, in situ hybridisation.

Part of this study was presented in the 84 th Annual meeting of Japanese Society of Pathology and the abstract is published in Trans Soc Pathol fpn 1995;84:238.

Second Department of Pathology, Nagasaki University School of Medicine, Nagasaki,

Japan

M S Razzaque

T Taguchi

Correspondence to:

Dr M S Razzaque, Second Department of Pathology, Nagasaki University School of Medicine, 1-12-4, Sakamoto, Nagasaki 852 , Japan.

Accepted for publication 17 October 1995
The pathogenic mechanisms responsible for the initiation and progression of idiopathic membranous glomerulonephritis (MGN) are not clearly understood. About $40 \%$ of patients with MGN develop end stage renal failure. ${ }^{1}$ It is generally accepted that the abnormal accumulation of extracellular matrix (ECM) results in damage to the glomeruli in many kidney diseases. MGN, which is characterised by irregular thickening of the glomerular basement membrane (GBM), is thought to result from unusual metabolism of ECM. Type IV collagen, heparin sulphate proteoglycan and laminin together comprise the spike-like structures and the newly synthesised GBMlike matrix of the thickened GBM in MGN and membranous lupus nephritis. ${ }^{2}$ Focal immunostaining of type III collagen in the glomeruli of MGN has also been reported previously. ${ }^{3}$ The latter report is quite interesting as type III collagen also contributes significantly to the glomerular and tubulointerstitial damage observed in several renal diseases-for example, diabetic nephropathy ${ }^{45}$ and benign nephrosclerosis. ${ }^{67}$ It is unclear, however, what types of cells are responsible for synthesising type III collagen in human MGN. The present study was undertaken, therefore, to elucidate the cellular localisation of $\propto 1$ (III) mRNA in MGN.

\section{Methods}

Renal biopsy specimens were obtained from 10 patients showing the histological changes characteristic of MGN (as described in the WHO classification of glomerular diseases). Five samples of renal tissue with no noticeable abnormalities, obtained at renal surgery, served as controls. All of the renal tissue specimens (biopsy and surgical) were examined routinely by light, immunofluorescence and electron microscopy. For examination by light microscopy, the specimens were fixed in $10 \%$ formalin, embedded in paraffin wax and were stained with haematoxylin and eosin, periodic acid Schiff (PAS), periodic acid Schiff methenamine silver (PAM), and Masson's trichrome. For electron microscopy, the tissue samples were fixed in $2.5 \%$ glutaraldehyde, impregnated with osmic acid and embedded in Epon. Ultra thin sections were double stained with lead citrate and uranyl acetate. The antigenic markers for $\operatorname{IgG}, \operatorname{IgA}, \operatorname{IgM}, \mathrm{C}_{3}$ and $\mathrm{C} 1 \mathrm{q}$ were also examined on frozen sections by immunofluorescence microscopy.

\section{IMMUNOHISTOCHEMISTRY}

Formalin fixed, paraffin wax sections, $4 \mu \mathrm{m}$ thick, were stained immunohistochemically with a monoclonal antibody directed against human type III collagen (Fuji Chemicals, Japan) as described previously. ${ }^{4-7}$ Briefly, the paraffin wax sections were dewaxed in xylene and rehydrated through a series of graded ethanols. Endogenous peroxidase was blocked by incubating the sections for 20 minutes in $0.3 \%$ hydrogen peroxide. After washing, the sections were incubated with rabbit serum (30 minutes) to block non-specific binding. The sections were then allowed to react with the primary antibody (diluted 1 in 25 with $0.01 \mathrm{M}$ phosphate buffered saline (PBS)) for one hour and processed further by the Streptavidin-biotin method using a Histofine SAB kit (Nichirei, Tokyo, Japan) according to the manufacturer's instructions. As a negative control, the primary 
antibody was replaced with normal mouse serum diluted with $0.01 \mathrm{MPBS}$ at a similar concentration to that used for the test sections.

\section{IN SITU HYBRIDISATION}

Oligo DNA probes

A 45 base sequence complementary to human pro $\alpha 1$ (III) chain mRNA (919 to 963$)^{8}$ was used to detect type III collagen synthesising cells. On searching GenBank, we found no significant homology between this 45 base sequence and any of the known sequences other than that of the pro $\alpha 1$ (III) chain. The oligo DNA (sense and antisense) probes were synthesised using an automatic DNA synthesiser (Applied Biosystems, California, USA) and were $3^{\prime}$ end labelled with digoxigenin (Boehringer Mannheim, Mannheim, Germany). Labelling was verified immunochemically on a nitrocellulose filter using an antibody directed against digoxigenin (Boehringer Mannheim). Dot blot hybridisation was used to confirm the specificity of the probes: when the digoxigenin labelled antisense pro $\alpha 1$ (III) oligo DNA probe was hybridised with the sense probe on a nitrocellulose filter, at least $10 \mathrm{pg}$ of the sense probe was detected (data not shown).

\section{Experimental procedure}

In situ hybridisation was carried out as described previously by Koji and Brenner. ${ }^{9}$ Briefly deparaffinised sections, $4 \mu \mathrm{m}$ thick, were treated successively with $0.3 \%$ hydrogen peroxide (30 minutes), $0.2 \mathrm{~N} \mathrm{HCl}$ (20 minutes), $0 \cdot 2 \%$ Triton $\mathrm{X}-100$ (10 minutes), and proteinase $\mathrm{K}\left(10 \mu \mathrm{g} / \mathrm{ml}, 37^{\circ} \mathrm{C}, 15\right.$ minutes). The sections were post-fixed with $4 \%$ paraformaldehyde in PBS (five minutes), immersed in $2 \mathrm{mg} / \mathrm{ml}$ glycine (30 minutes) and kept in $40 \%$ deionised formamide in $4 \times$ SSC $(1 \times \mathrm{SSC}=0.15 \mathrm{M}$ sodium chloride, $0.015 \mathrm{M}$ sodium citrate, $\mathrm{pH} \mathrm{7.0)}$ until used. Probes $(4 \mu \mathrm{g} / \mathrm{ml})$ were hybridised overnight at $37^{\circ} \mathrm{C} .{ }^{469}$ Slides were then washed in $50 \%$ formamide in $2 \times$ SSC and $0.5 \times$ SSC, $2 \times$ SSC, and PBS The sections were incubated in blocking solution $(5 \%$ bovine serum albumin, $500 \mu \mathrm{g} / \mathrm{ml}$ normal sheep IgG, $100 \mu \mathrm{g} / \mathrm{ml}$ salmon testicular DNA, and $100 \mu \mathrm{g} / \mathrm{ml}$ yeast tRNA in PBS) for one hour and then for 15 to 17 hours in horseradish peroxidase sheep anti-digoxigenin antibody, diluted 1 in 200 in blocking solution. The sections were washed in $0.075 \%$ Brij35 in PBS for $4 \times 15$ minutes. Hybridisation was visualised using a solution containing $3,3^{\prime}$-diaminobenzidine $/ 4 \mathrm{HCl}$, hydrogen peroxide, cobalt, and nickel. ${ }^{10}$ Periodic-acid Schiff was used as counterstain. ${ }^{45}$ The intensity of the hybridisation signal was graded semiquantitatively as follows: $0=$ no signal; $+=$ weak signal; $++=$ moderate signal; $+++=$ strong signal.

\section{Control experiments}

The following experiments were carried out to verify the specificity of the hybridisation signals: (1) serial sections were reacted with the hy-

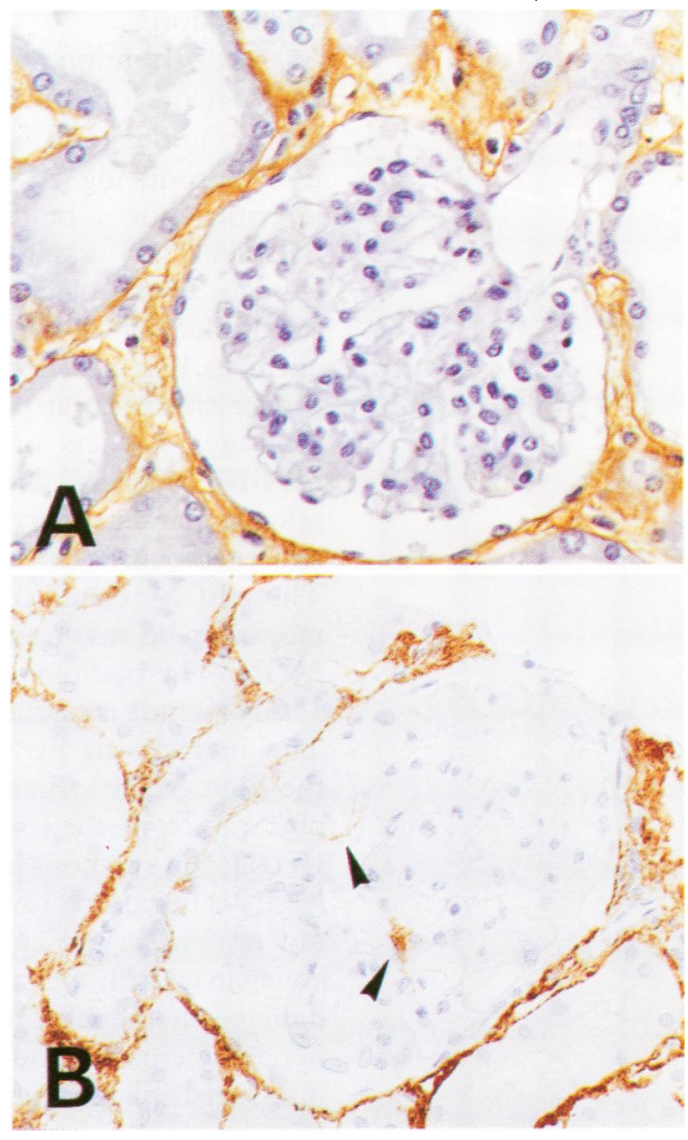

Immunohistochemical staining of type III collagen in a control (panel $A$ ) and in a MGN (panel B) glomerulus. Note the focal intraglomerular immunostaining for type III collagen (arrowhead) in the MGN sample.

(Immunoperoxidase technique, haematoxylin counterstain.)

bridisation solution containing the digoxigenin labelled sense oligo DNA probe or hybridisation solution excluding the probe; (2) consecutive sections were pretreated with RNaseA $\left(100 \mu \mathrm{g} / \mathrm{ml}, 37^{\circ} \mathrm{C}\right.$, one hour) before post fixation; and (3) adjacent sections were hybridised with a solution containing a 50 -fold excess of the unlabelled antisense oligo DNA probe in addition to digoxigenin labelled antisense oligo DNA probe.

\section{Results}

In the control samples type III collagen was not detected in the glomeruli but was stained intensely in the interstitium (figure, panel A). By contrast, focal immunostaining for type III collagen was found occasionally in the glomeruli of MGN samples (figure, panel B). On hybridising the paraffin wax sections with the digoxigenin labelled antisense oligo DNA probe, no signal was detected in the glomeruli of the control samples; however, moderate to strong signals $(++$ to +++$)$ for $\alpha 1$ (III) chain mRNA were seen in glomerular epithelial cells and mesangial cells in the samples from patients with MGN (data not shown). Positive signals for $\alpha 1$ (III) chain mRNA were detected in the glomeruli of all of the MGN cases. 


\section{Discussion}

As the distribution and cellular origin of all the components of the ECM in MGN are not clearly understood as yet, identification of ECM producing cells at the molecular level is critical for a better understanding of the mechanisms underlying the pathological changes taking place in MGN. Elucidation of the molecular mechanisms involved in liver cirrhosis has facilitated monitoring of disease progression and, at present, the ECM related cleavage products of the collagen precursor NPIIIP collagen ${ }^{11}$ are regarded as the most reliable markers of active hepatic fibrinogenesis and therapeutic efficacy of antifibrotic drugs. These ECM related collagen cleavage products may also be involved in the pathogenesis of MGN. The pathological changes occurring in MGN include irregular thickening of the GBM. The mechanism by which this alteration of the glomerular structure takes place remains obscure. None the less, the importance of type III collagen synthesis by intraglomerular cells in MGN is beginning to be understood. Although not present in the control glomeruli, type III collagen contributes substantially to glomerular damage in diabetic nephropathy and benign nephrosclerosis ${ }^{46}$ and it is possible that this interstitial collagen has a role in the modulation of the disease process in MGN. In the present study $\alpha 1$ (III) mRNA and its translated protein were detected in the glomeruli of MGN samples. These results compliment the findings of Del Pozo et al, ${ }^{12}$ who demonstrated the presence of type III collagen in GBM in nail patella syndrome. Similarly, Floege $e t$ al $^{13} \mathrm{dem}$ onstrated that active Heymann nephritis was accompanied by increased expression of interstitial type I collagen mRNA, despite the lack of glomerular immunostaining for type I collagen, and the transient expression of type I collagen mRNA and its protein in glomerular epithelial cells in passive Heymann nephritis.
In summary, intraglomerular cells synthesise type III collagen in MGN. Excessive interstitial type III collagen synthesis by mesangial and epithelial cells in MGN may augment structural damage of the GBM. Further study of the factors regulating type III collagen synthesis and its possible relation with disease progression in MGN is warranted.

We thank Ms R Togawa, Mrs Y Yamashita and Mrs S Nakanose for preparing the paraffin wax sections used in this study.

1 Ramzy MH, Cameron JS, Turner DR, Neild GH, Ogg CS, Hicks J. The long-term outcome of idiopathic membranous nephropathy. Clin Nephrol 1981;16:13-19.

2 Haramoto T, Makino H, Ikeda S, Wieslander J, Ota Z Ultrastructural localization of the three major basemen membrane components - type IV collagen, heparan sulfate proteoglycan and laminin - in human membranous glomerulonephritis. Am $\mathcal{f}$ Nephrol 1994;14:30-6.

3 Yoshioka K, Takemura T, Tohda M, Akano N, Miyamoto $\mathrm{H}$, Ooshima A, et al. Glomerular localization of type III collagen in human kidney disease. Kidney Int 1989;35. 1203-11.

4 Razzaque MS, Koji T, Taguchi T, Harada T, Nakane PK. In situ localization of type III and type IV collagen expressing cells in human diabetic nephropathy. F Patho 994;174:131-8.

5 Razzaque MS, Koji T, Horita Y, Nishihara M, Taguchi T, Harada T, et al. Synthesis of type III collagen and type IV collagen by tubular epithelial cells in diabetic nephropathy. Pathol Res Pract (in press).

6 Razzaque MS, Koji T, Kawano H, Harada T, Nakane PK, Taguchi T. Glomerular expression of type III and type IV collagens in benign nephrosclerosis: immunohistochemical and in situ hybridization study. Pathol Res Pract 1994;190:493-9.

7 Razzaque MS, Cheng M, Horita Y, Nishihara M, Harada $T$, Taguchi T. Immunohistochemical analysis of type III and IV collagens in tubulointerstitial damage in human benign nephrosclerosis. F Int Med Res (in press)

8 Ala-Kokko L, Kontusaari S, Baldwin TC, Kuivaniemi $\mathrm{H}$ Prockop DJ. Structure of cDNA clones coding for the entire prepro $\alpha 1$ (III) chain of human type III procollagen. Differences in protein structure from type I procollagen and conservation of codon preferences. Biochem f 1989; 260:509-16.

9 Koji T, Brenner RM. Localization of estrogen receptor messenger ribonucleic acid in rhesus monkey uterus by nonradioactive in situ hybridization with digoxigeninlabeled oligodeoxynucleotides. Endocrinology 1993;132: 382-92.

10 Adams JC. Heavy metal intensification of DAB-based HRP reaction product. $\mathcal{F}$ Histochem Cytochem 1981;29:775.

11 Gabrielli GB, Corrocher R. Hepatic fibrosis and its serum markers: a review. Dig Dis 1991;9:303-16.

12 Del Pozo E, Lapp H. Ultrastructure of the kidney in the nephropathy of the nail patella syndrome. Am 7 Clin Pathol 1970;54:845-54

13 Floege J, Johnson RJ, Gordon K, Yoshimura A, Campbel $\mathrm{C}$, Iruela-Arispe $\mathrm{L}$, et al. Altered glomerular extracellular matrix synthesis in experimental membranous nephropathy. Kidney Int 1992;42:573-85. 